\title{
Assessment System of Local Government Projects Prototype in Indonesia
}

\author{
Herri Setiawan ${ }^{1}$, Husnawati $^{2}$, Tasmi $^{3}$ \\ Department of Informatics, Faculty of Computer Science, Universitas Indo Global Mandiri, Palembang, Indonesia ${ }^{1}$ \\ Department of Computer System, Faculty of Computer Science, Universitas Indo Global Mandiri, Palembang, Indonesia, 2,3
}

\begin{abstract}
The purpose of this research is to build an application that is used for project evaluation and provide recommendations on project performance in local government agencies. In this study, project evaluation was carried out using the Group Decision Making (GDM) model based on the Group Decision Support System (GDSM) concept. The project output and outcome parameters used by the Decision Maker (DM) use a hybrid of the Multi-Criteria Decision Making (MCDM) and Project Management Body of Knowledge (PMBOK) methods to reduce subjectivity in scoring qualitative data and to determine project ratings from all DMs. Copeland Score voting method. The results of application computing on the implementation of Group Decision Support System (GDSS) and MCDM indicate that the project ranking process will be faster and more accurate. The results of the sensitivity test show that two criteria have a great influence on project performance so that they have a very important role in project evaluation.
\end{abstract}

Keywords-Group Decision Making (GDM); Group Decision Support System (GDSS); MULTI-CRITERIA DECISION MAKING (MCDM); Project Management Body of Knowledge (PMBOK); local government

\section{INTRODUCTION}

Projects in government agencies are part of the program, and consist of a set of actions to mobilize resources, either in the form of personnel (HR), capital goods including equipment and technology, funds, or a hybrid of some or all of these types of resources as inputs to produce outputs. in the form of goods/services. Measurement of project performance in government agencies, including the current project, has a weakness because it does not reflect the project evaluation that is generally carried out, which is only based on the percentage of achievement of the planned level of achievement of each project performance indicator as determined through the successful realization of the indicators in question [1].

The calculation of the percentage of achievement of the planned level of activity achievement used is based on the absorbed funds and the realization of output between the realization and the plan, which is stated in the administrative document of the Government Agency Performance Accountability Report (LAKIP). There can be no correlation between the output produced and the expected outcome. In the current LAKIP measurement method, including project evaluation, the criteria used to measure organizational performance are only limited to quantitative criteria, namely timeliness of implementation and effectiveness in the use of financial resources. Research conducted [2] developed a description of how to determine KPIs in ICT projects to get ideas and solutions in evaluating ICT projects.

Based on the problems an institutional decision-making system is needed which is an activity that can be carried out by individuals, groups, or organizations. Also, special steps need to be taken so that the group's decisions can be agreed upon and binding on the various parties involved. According to the viewpoint of software engineering, instances of existing applications that utilize notoriety as well as trust approaches incorporate shared, peer to peer (P2P) communications, internet business, e-advertising, multi-specialist frameworks, web search tools and Group Decision Making (GDM) situations [3][4]. The decision is the result of an evaluation of the selection of the best alternative, which involves the relevant parties. With the number of considerations and desires that must be considered, decision-making needs to listen to the considerations of many people.

One solution that is widely offered in making decisions using computing is the Group Decision Support System (GDSS). The model was made with various approaches, one of which used an approach to GDSS [5]. This model is formulated regarding social choice theory. The model is structured using a voting mechanism, in such a way that it allows each decisionmaker to express their choice. Research shows that this model can accommodate Multi-Criteria Decision Making (MCDM). In modeling, the choice (vote) of the DM is considered. MCDM has played a role as an instrument for many individuals to choose candidates or alternatives. From its meaning, multi-criteria decision-making (MCDM) is used to determine the best alternative from several alternatives based on certain criteria [6].

There have been many previous studies using this method such as [7][8][9][10][11][12]. One of the popular methods used for this is the Analytic Hierarchy Process (AHP). This method uses human perception input and can process qualitative data, resulting in a comprehensive decision-making model. This is because AHP can solve multi-objective and multi-criteria problems based on the comparison of preferences of each element in the hierarchy. However, the AHP method has a weakness because the main input is in the form of perception so that it involves subjectivity, this will be a problem if the DM gives a wrong assessment. Another popular method used within the project scope is the Technique for Order Preference by Similarity to Ideal Solution (TOPSIS). This method is used because it is closely related to the benefits (benefits) and costs (costs) in a project. This method is based on the concept that the best-chosen alternative not only has the shortest distance 
from the positive ideal solution (benefit) but also has the longest distance from the negative ideal solution (cost). The main weakness of the TOPSIS method is that it does not provide elicitation of weights and check the consistency of the assessment [13].

This study will create a new model to facilitate the achievement of consensus among DM while respecting different preferences, interests, and values. GDSS is expected to expand DM capabilities, but not to replace DM assessment. What is to be realized is "a new decision model that is implemented in a computer-based system that supports a group of people who are members of the same task or goal and have one particular tool that functions to interconnect the people in the group". This is known as the Group Decision Support System (GDSS) [14].

The purpose of this research is to develop a Group Decision Support System (GDSS) model for project evaluation, which not only fulfills administrative or normative needs but also provides a more objective evaluation. In this study, assessment criteria will be used that can represent the assessment in the scope of project evaluation, especially evaluation of projects in local government agencies. Considering aspects of the applicable legislation, Decision Makers (DM) are involved, namely: Government Institution Executives, Project Management Work Units, Business Process Owners Units, and the Community represented by DPRD, to provide assessments and evaluations of project implementation in institutions local government. Then, in the evaluation process, a GDSS concept was used. The GDSS concept can overcome inconsistencies that may occur in decision making because with GDSS decisions are made based on a mathematical calculation model. Project evaluation is carried out by DMs on output and outcome parameters, using a hybrid MCDM method based on the established criteria. In the weighting of the criteria used weighting techniques in the AHP method. Furthermore, the weight of the resulting criteria is used as input for the TOPSIS method to generate project rankings for each DM. At this stage, scoring of project qualitative data is carried out based on the Project Management Body of Knowledge (PMBOK) to reduce DM subjectivity. As the last step, to determine the project ranking of all DMs, the Copeland Score voting method was used.

\section{LITERATURE REVIEW}

The appraisal process is an important step in evaluation because it underlies the successful evaluation of a project. Through a systematic literature review, several project evaluations models have been identified and analyzed. The results show that the effectiveness and efficiency of evaluation are increasingly important for a project [15]. In this regard, several researchers have implemented MCDM methods, both in the DSS or SPKK [16][8][9][10]. Many organizations realize the importance of the MCDM method because the use of the MCDM method increases effectiveness in decisionmaking. As in the research conducted [8], it is stated that the first step to reducing the risk of project failure is to choose the optimal project. The effectiveness of the criteria in selecting the most optimal project was identified and defined by the
MCDM approach, using the AHP and TOPSIS methods. The use of the proposed model can help companies facilitate a systematic approach in making the right project selection decisions.

Effective and efficient project selection has an important meaning in every organization because the decision-making process to assess the feasibility of a project is very complex [16]. The method used in this research is AHP and Moora. Modeling is based on various types of logic, considering the existence of various criteria, the objectives of the decisionmaker, and the nature of the complexity of the evaluation process. According to him, the main advantage of MCDM is that it provides decision-making by analyzing complex problems, can aggregate criteria in the evaluation process, and provide scope for decision-makers to actively participate in the decision-making process.

Research [9] proposes the application of the MCDM framework to monitor and measure ongoing project performance. Linear Programming (LP) and MCDM methods are used to evaluate decision-making on the selection of project priorities. An MCDM approach is also proposed [17] to evaluate Product Development (PD) effectively. After the criteria hierarchy is built, the weight of the criteria is calculated using the AHP method. The Vikor method is used to rank the results at a later stage. The results of the sensitivity analysis show that the AHP-Vikor integrated model can accommodate the evaluation of the criteria weights. And the results of empirical studies show that the proposed evaluation framework can solve the problems that arise.

The Project Management Body of Knowledge (PMBOK) was developed by the Project Management Institute (PMI), an organization in America specializing in project management development. PMBOK is a guide that contains knowledge in project management and is always updated within a certain time. Project management is the application of knowledge, skills, tools, and techniques in project activities to meet project needs. PMBOK generally develops 9 (nine) areas that must be understood in project management, namely: Project Integration Management, Project Scope Management, Project Time Management, Project Cost Management, Project Quality Management, Project Human Resource Management, Project Communication Management, Project Risk Management, Project Procurement Management [18]. According to [19], managing ICT projects is seen as a challenging activity, because it involves a balanced portion of tangible and intangible resources. Various studies of independent institutions in America and Europe say that more than $70 \%$ of ICT projects are considered a failure, in the sense of not meeting the targets set previously at the planning stage. One of the causes of this failure is due to the indiscipline of stakeholders who are directly involved with ICT projects in complying with the standard project implementation and control methodologies that have been outlined.

Copeland Score is one of the voting methods whose technique is based on reducing the frequency of wins with the frequency of defeats from pairwise comparisons [20]. group decision-making to determine gene abnormalities in cancer. 


\section{MethodOLOGY}

This research will use program/activity data in districts/cities of South Sumatra Province, Indonesia. This study builds a project evaluation GDSS model in local government agencies in determining the best project ranking, using a hybrid method of MCDM and PMBOK. The framework of this research can be seen in Fig. 1.

\section{A. Proposed Model}

The proposed model is a Group Decision Making (GDM) model based on the GDSS concept, using the methods in Multi-Attribute Decision Making (MADM) to determine the best project from several alternatives based on several predetermined criteria. Then the MADM combination method in the SPKK will be developed based on the Analytical Hierarchy Process (AHP) method, Technique for Order Preference by Similarity to Ideal Solution (TOPSIS), and Copeland Score, each of which has its role.

Based on Fig. 1, to determine the weight of the criteria, the weighting technique contained in the AHP method is used, then the results of the weighting of these criteria will be input in the TOPSIS calculation which is used to determine the ranking as a result of evaluating the performance of these activities. At the scoring stage, project qualitative data is based on the Project Management Body of Knowledge (PMBOK) to reduce DM subjectivity.

From the TOPSIS calculation, the project ranking for each $\mathrm{DM}$ is generated, and to unify the differences in preferences between DMs, the Copeland Score method is used as a voting method to determine the best project ranking from all decisionmakers. Fig. 2. is a GDM model for the evaluation of ICT projects in government agencies.

In the GDM component, each component plays a role in the decision-making process as described. Each DM performs a weighting against the assessment criteria it has. The next stage is that each DM assigns a score to the alternative (ICT project) so that the project ranking of each DM is generated. The final step is to rank projects from all DMs using the voting method as a result of group decisions. Fig. 3. describes the decisionmaking process carried out individually and in groups in the GDM model.

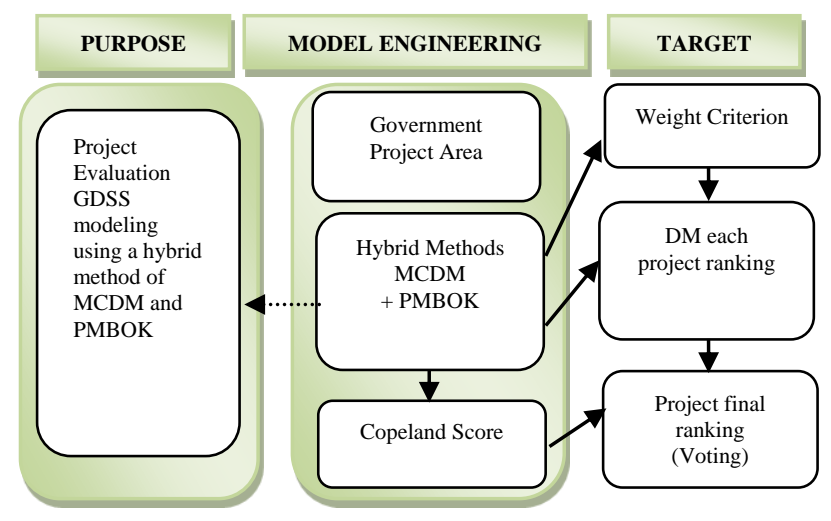

Fig. 1. Framework.

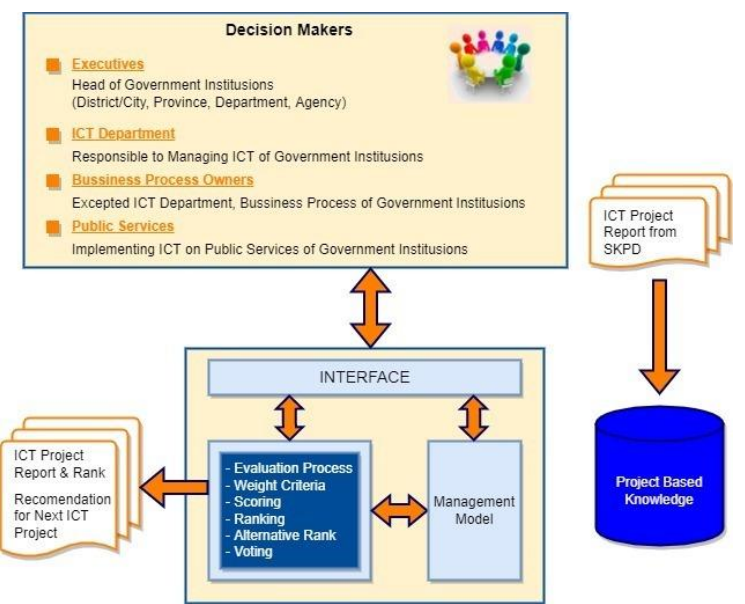

Fig. 2. GDM Model for Evaluation of the Proposed Local Government Information and Communication Technology (ICT) Project.

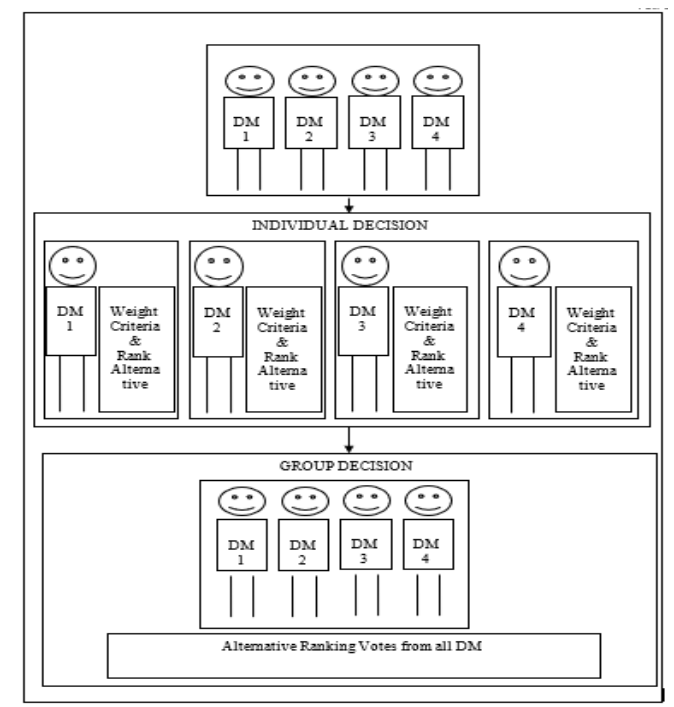

Fig. 3. Individual and Group Decision Making Process in GDM Model.

\section{B. Calculating Weight Algorithm}

In this section, a combination of the AHP and TOPSIS methods is carried out with the preparation of a pairwise comparison matrix and weighting the criteria, with the goal of determining whether matrix $\mathrm{A}$ is consistent or not as shown in Fig. 4.

1) Each Decision Maker $\left(\mathrm{DM}_{\mathrm{i}}\right)$ has its assessment criteria $\left(\mathrm{C}_{\mathrm{ij}}\right)$.

2) In process two, matrix $A$ is squared, and in-process three matrix B is calculated. Matrix B is the sum of the elements in the same row of matrix A. Based on Matrix B, the eigenvectors are calculated so that Matrix E is obtained, described in process four.

3) The process of five, six, seven, and eight is to calculate the consistency of the index by deriving a matrix $\mathrm{C}$, which is the product of matrix A and matrix E. Based on matrix $\mathrm{C}$, it is determined whether matrix $\mathrm{A}$ is consistent. If it is consistent then the weight of the matrix A is calculated by calling the Algorithm for Calculating the Weighted Normalization Value. 
4) The output of this algorithm is the Criteria Weight (Wk) for each DM.

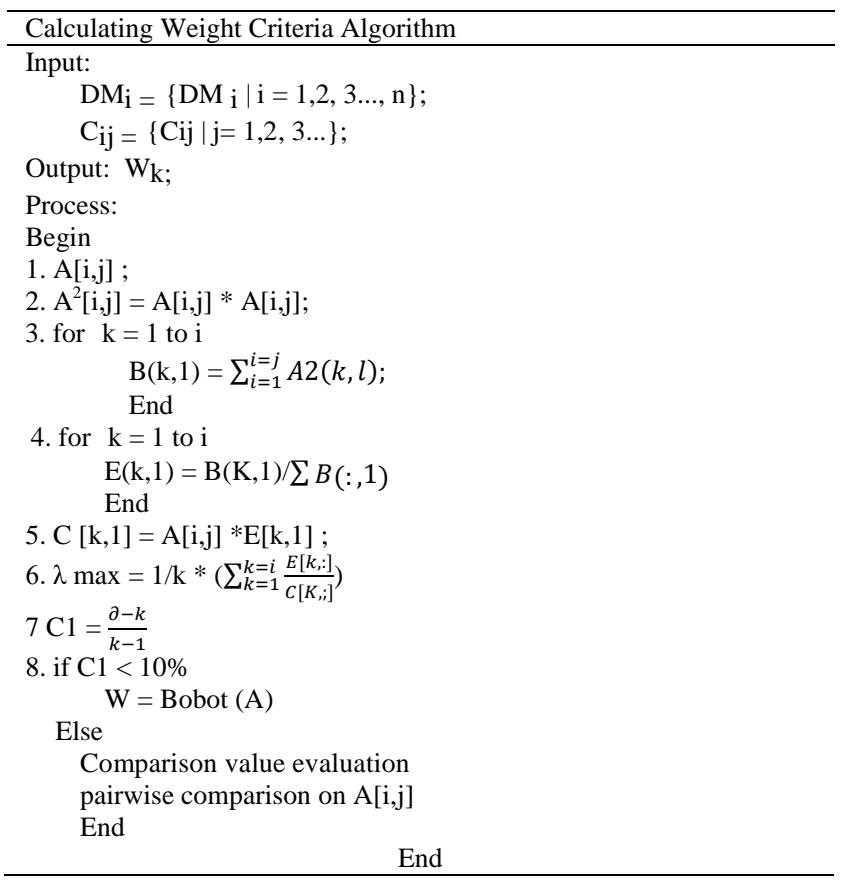

Fig. 4. Calculating Weight Criteria Algorithm.

\section{Algorithm for Calculating Normalization Value}

This algorithm explains the calculation of the normalized value of all alternatives for each criterion and calculates the normalized value of its weight as shown in Fig. 5.

1) The Decision Maker scores all ICT alternatives (projects) based on the assessment criteria it has so that after being converted based on the assessment rating, the results are in the form of a Scoring Matrix (SC).

2) Process 2 calculates the normalized value of all alternatives for each criterion (Matrix $\mathrm{X}$ ) and process 3 calculates the weighted normalized value (Matrix Y).

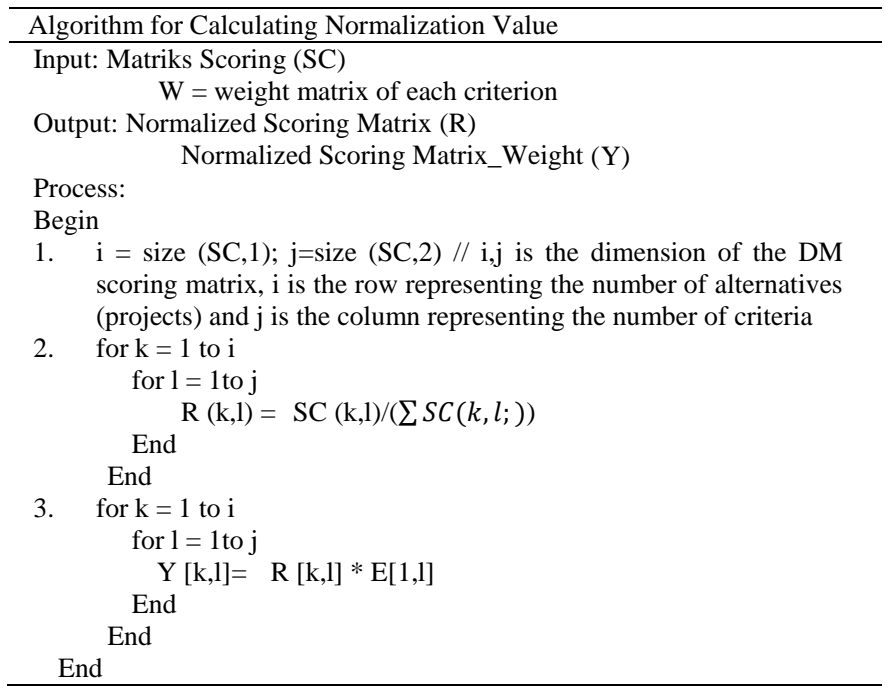

Fig. 5. Algorithm for Calculating Normalization Value.

\section{DESIGN AND IMPLEMENTATION SYSTEM}

\section{A. Design}

This study continues the research conducted by [21] who has not yet carried out the process of making web-based applications, so this study designs a Web-based GDSS Model Prototype [22] for Project Evaluation in Local Governments. The prototype is built based on a review of research results as described in the Literature Review, which relates to MCDM methods that can be applied in the scope of evaluating a project.

\section{B. Implementation}

This system is designed with several stages of implementation to produce an assessment that is used as the basis for making decisions on a project. The results of the application implementation are shown in Fig. 6 to 12.

Fig. 6 is a representation of the login page on the government project evaluation. On the page, the user and password fields are displayed, then the submit button. The home page contains display information regarding login access for users. In this case the user is an administrator who works in the government of the Province of South Sumatra. Users can login with User Name: admin and Password: admin, then press the login button, if the login is successful, it will go directly to the main menu.

When the user successfully logs in, they will immediately go to the main page (Dashboard) of the government project evaluation application. On the main page of the application, there are several menus and a comprehensive list of government projects as shown in the following image.

On the dashboard display from the Fig. 7, there are two menu sections located on the left side of the dashboard display and the upper right corner of the dashboard display. In the menu display on the left side of the dashboard, there are several menus, namely, Dashboard, Activities, Criteria, SKPD, Region, DM, Menu and Users.

From the Fig. 8 shown the activity page, all project activities that are being carried out will be displayed, to add activities, it can be done by selecting the add menu which is in the upper right corner of the activity page display. On the Add Activities page, the Add Activities form will appear, while the data that must be filled in this form include the name of the activity, the activity ceiling, volume and budget year.
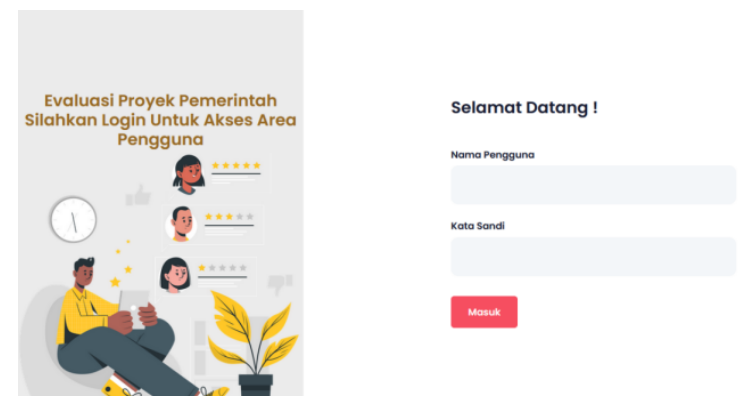

Fig. 6. Login Page. 


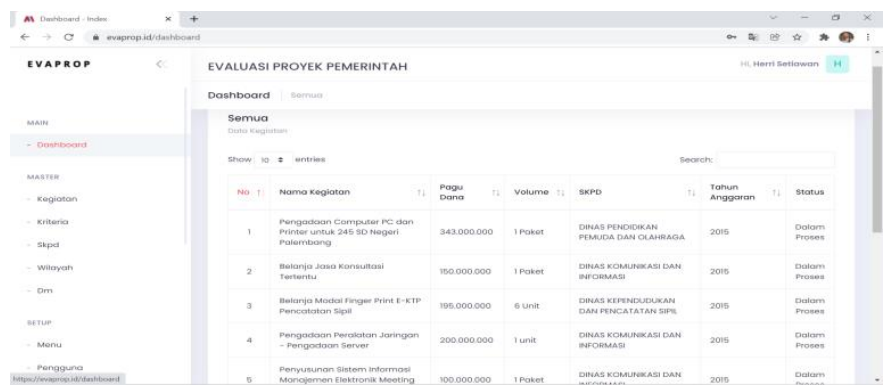

Fig. 7. Dashboard.

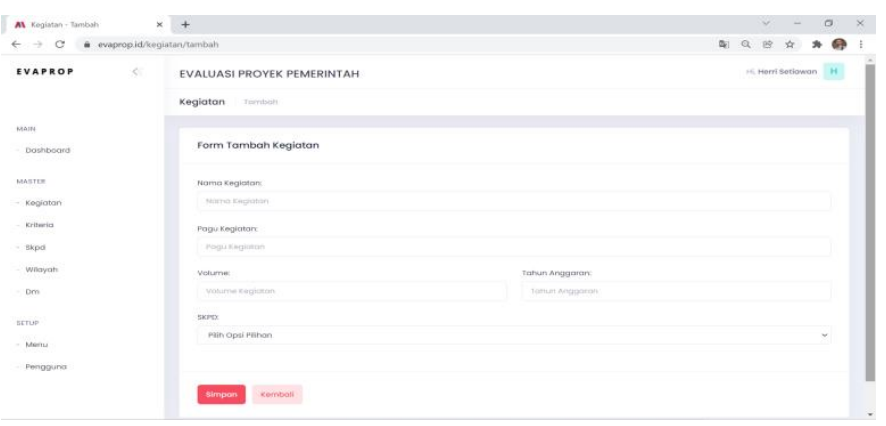

Fig. 8. Activity Setting.

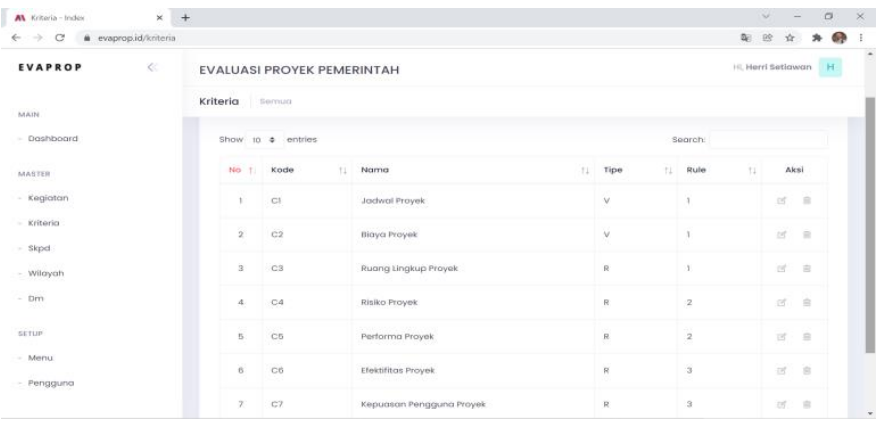

Fig. 9. Criterion Setting.

On the criteria page from Fig. 9, all the assessment criteria used will be displayed, adding criteria can be done by selecting the add menu which is in the upper right corner of the criteria display. On the Add Criteria page, the Add Criteria form will appear, which must be filled in, among others, criteria code, criteria name, criteria type and criteria rule. To save the newly added criteria can be done by selecting the save menu on the added criteria form.

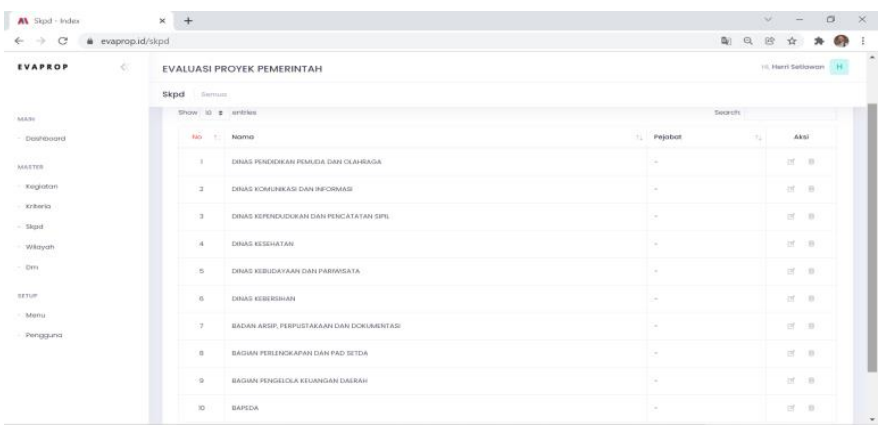

Fig. 10. Setting SKPD.
To fill in the SKPD on the added activity form, choose according to the list of available SKPD, to save new activities, select the save menu on the added activity form. On the Add SKPD page, the Add SKPD form will appear. To add a new SKPD, you must fill in the names of the SKPD and SKPD officials on the Add SKPD form. After all data is filled in, it can be saved by selecting the Save menu on the Add SKPD form.

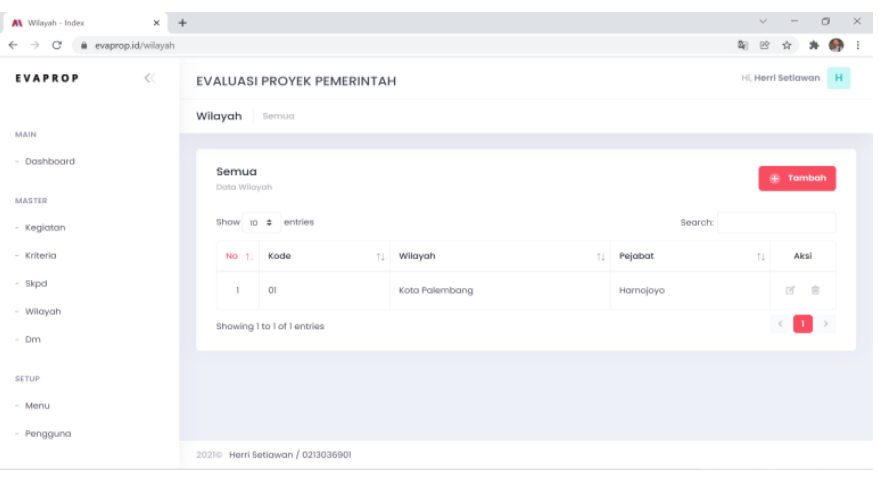

Fig. 11. Area Configuration.

In the regional menu, a regional data page will be displayed, to add regional data, it can be done by selecting the add menu in the upper right corner of the regional page. The Add Region menu will display the Add Region form. To add new area data, you must fill in all the required data on the Add Region form, including area code, area name and official name. After all data is filled in correctly, the data can be saved by selecting the save menu in the Add Region form.

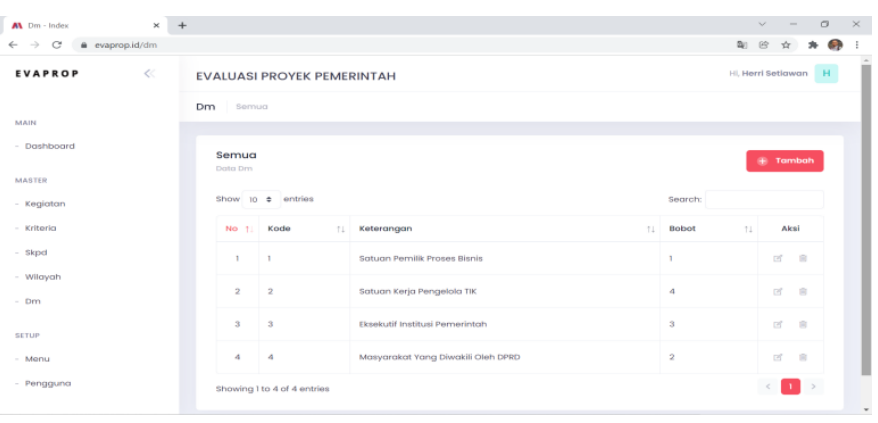

Fig. 12. Decision Maker.

Fig. 12 shows the Decision Maker (DM) page which is the result of weighting for codes $1,2,3$, and 4 based on the criteria page, each weighting being measured is the Business Process Owner Unit, ICT Management Work Unit, Government Institution Executive, and Communities Represented By the Council. The weighting in each of these categories will be measured based on the criteria that have been determined on the criteria page.

\section{RESUlt AND ANALYSIS}

In the implementation, DM1 will evaluate each alternative (project) based on 3 (three) criteria $\mathrm{C}=\{\mathrm{C} 1, \mathrm{C} 2, \mathrm{C} 3), \mathrm{DM} 2$ will evaluate each alternative based on 2 (two) criteria $C=\{C 4$, C5 \}, DM3 and DM4 will evaluate each alternative based on 2 (two) criteria $\mathrm{C}=\{\mathrm{C} 6, \mathrm{C} 7\}$. 
DM1 determines the relative importance between the criteria of Project Schedule (C1), Project Cost (C2), Project Scope (C3). The assessment uses the weighting standard with a scale ranging from 1 to 9 and vice versa, the values of these criteria, according to a DM1 pairwise comparison matrix, are as follows:

$$
\begin{array}{c|ccc}
\multicolumn{1}{c}{} & \mathrm{C} 1 & \mathrm{C} 2 & \mathrm{C} 3 \\
\mathrm{C} 1 & 1 & 0.5 & 0.3 \\
\mathrm{C} 2 & 2 & 1 & 0.5 \\
\mathrm{C} 3 & 3 & 2 & 1
\end{array}
$$

This stage calculates the priority weighting by finding the eigenvector value of the A matrix through the following process. Squaring the A matrix.

$\left|\begin{array}{ccc}1 & 0.5 & 0.3 \\ 2 & 1 & 0.5 \\ 3 & 2 & 1\end{array}\right| \times\left|\begin{array}{lll}1 & 0.5 & 0.3 \\ 2 & 1 & 0.5 \\ 3 & 2 & 1\end{array}\right|=\left|\begin{array}{lll}2.9 & 1.6 & 0.85 \\ 5.5 & 3 & 1.6 \\ 10 & 5.5 & 2.9\end{array}\right|$

The next process is to add up the elements of each row of the A2 matrix so that a matrix is obtained. Then arrange matrix $\mathrm{B}$, and add up all elements of matrix $\mathrm{B}$ with the following values below.

$B=\left[\begin{array}{c}5.3500 \\ 10.1000 \\ 18.4000\end{array}\right]$

From the B matrix that has been obtained in the above step, then normalization is carried out on the $\mathrm{B}$ matrix to obtain the eigenvector value of the $\mathrm{B}$ matrix.

$E=\left[\begin{array}{l}e 1 \\ e 2 \\ e 3\end{array}\right]$

$\mathrm{e}_{1}=5.3500 /(5.3500+10.1000+18.4000)=0.1581$.

$\mathrm{e}_{2}=10.1000 /(5.3500+10.1000+18.4000)=0.2983$.

$\mathrm{e}_{3}=18.4000 /(5.3500+10.1000+18.4000)=0.5436$.

$E=\left[\begin{array}{l}0.1581 \\ 0.2983 \\ 0.5436\end{array}\right]$

The three processes above are repeated and at the end of each iteration, the difference between the eigenvector matrix $\mathrm{E}$ values obtained and the previous eigenvector matrix $E$ values is sought until a number close to zero is obtained. The matrix E obtained in the last step shows the priority of the criteria indicated by the coefficient of the eigenvector value so that the eigenvector matrix E obtained is:

$E=\left[\begin{array}{l}0.1638 \\ 0.2972 \\ 0.5390\end{array}\right]$

To measure the consistency of the matrix, the first thing to do is to calculate the Consistency Index (CI) by calculating the weighted vector number. The product of the matrix A on the Eigenvalue (matrix E).

$$
\left[\begin{array}{ccc}
1 & 0.5 & 0.3 \\
2 & 1 & 0.5 \\
3 & 2 & 1
\end{array}\right] \times\left[\begin{array}{l}
0.1638 \\
0.2972 \\
0.5390
\end{array}\right]=\left[\begin{array}{l}
0.4921 \\
0.8941 \\
1.6248
\end{array}\right]
$$

quotient above by the number of elements present, the result is called max $(\lambda \max )$

$\lambda \max =1 / 3 *(0.4972 / 0.1638)+(0.8943 / 0.2972)+$ $(1.6248 / 0.5390)$

$\lambda \max =3.0092$

So that the value of the Consistency Index

$(\mathrm{CI})=(3.0092-3) /(3-1)=0.0066$

The matrix has 3 (three) elements, so the IR value is 0.58 . So the value of $\mathrm{CR}$ is $0.0066 / 0.58=.0 .0079$. Because the CR value is less than $10 \%$, the data judgment is correct. It can be concluded that matrix $\mathrm{A}$ is quite consistent.

From the values that have been tested in this study, sensitivity analysis was carried out by changing the weight of the criteria. Changes in the weight value of each criterion are carried out by lowering or increasing the weight to see whether the alternative ranking results (projects) tend to change or not. The trial weight changes were increased or decreased from the initial values of $10 \%, 20 \%$, and $30 \%$. Sensitivity analysis was performed against all criteria. Sensitivity analysis on criteria C1 (Project Schedule) Based on the graph of the results of sensitivity analysis against criteria C1 (Project Schedule) as shown in Fig. 13, test for changes in the weight of the criteria there is a change in the value of the alternative (project schedule).

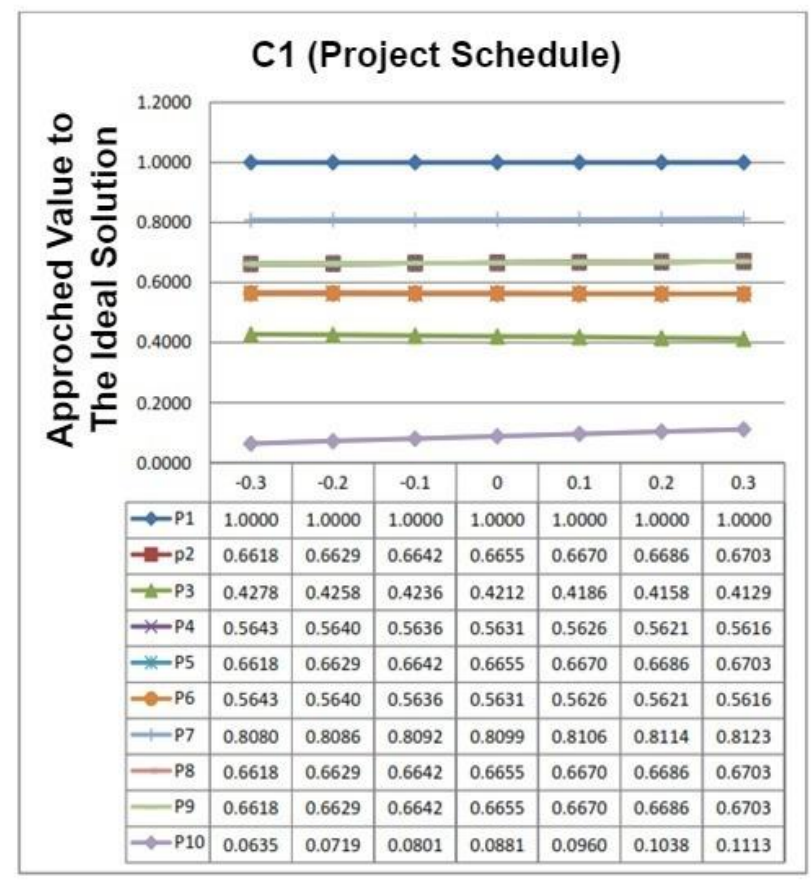

Fig. 13. Sensitivity Analysis on Criteria C1 (Project Schedule). 


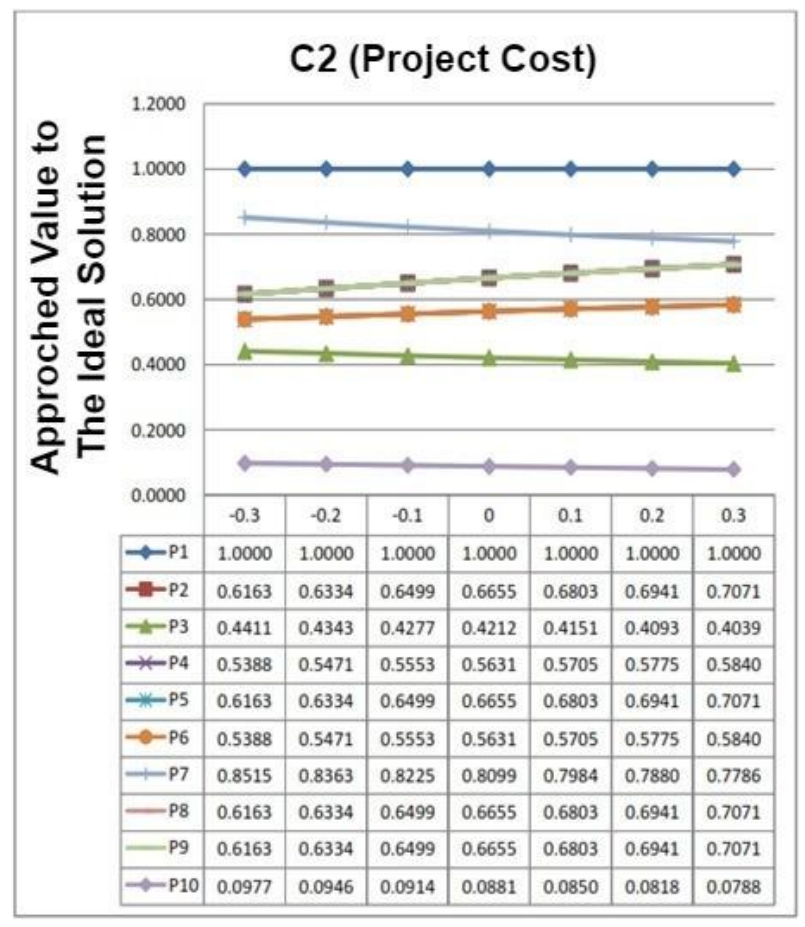

Fig. 14. Sensitivity Analysis on Criteria C2 (Project Cost).

Based on Fig. 14, the graph below shows the results of the sensitivity analysis against the C2 (Project Cost) criteria. The test to changes in the weight of the criteria results in a change in the value of the alternative (project cost).

The results of the sensitivity analysis against the $\mathrm{C} 3$ criteria (Scope of the Project) as shown in Fig. 15, the test of changes in the weight of the criteria changes in the value of the alternative (project).

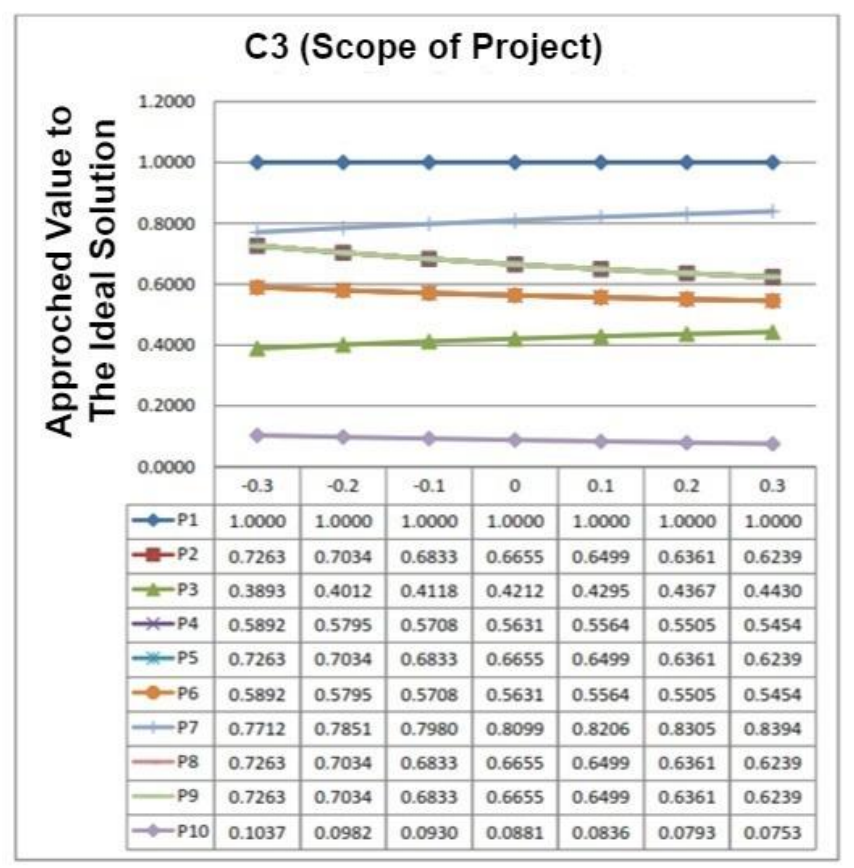

Fig. 15. Sensitivity Analysis on Criteria C3 (Scope of the Project).

\section{CONCLUSION}

This study resulted in a GDM model for evaluating ICT activities in local government agencies in Indonesia using the GDSS concept. DM involved consists of 1) Executive government institutions, 2) ICT Management Unit, and 3) Business Process Owner Unit, and the community represented by DPRD. From the values that have been tested in this study, sensitivity analysis was carried out by changing the weight of the criteria. Changes in the weight value of each criterion are carried out by lowering or increasing the weight to see whether the alternative ranking results (projects) tend to change or not. The trial weight changes were increased or decreased from the initial values of $10 \%, 20 \%$, and $30 \%$. Sensitivity analysis was performed against all criteria.

Determination of the best ICT project from several alternatives using several determining qualitative and quantitative parameters and criteria. In the project output parameters, the criteria used in the assessment are project schedule, project cost, project scope, project risk, and project performance. While the outcome parameters are projected effectiveness criteria and project user satisfaction. With the guidance of the Project Management Body of Knowledge (PMBOK), the provision of qualitative data scoring projects has an assessment basis to reduce the subjectivity of DM.

At the main stage of this study, we concluded that the method succeeded in parsing the draw voting process by developing it by adding a winning gap (distance) between alternatives during the pairwise contest and then multiplying the existing gap by the weight or population of DM. the results of the model trial case study, the voting results of all DMs on ten (10) ICT projects in the Palembang city government, it was found that and also the results of the sensitivity test against the three criteria affected project evaluation. In the future, we will try a ranking system to get results that can determine transparent winners in a project in government.

\section{ACKNOWLEDGMENT}

Thanks to Indo Global Mandiri Foundation (Yayasan Indo Global Mandiri, IGM) and Informatics Engineering Faculty of Computer Science, Indo Global Mandiri University.

\section{REFERENCES}

[1] Lembaga Administrasi Negara Republik Indonesia, "Pedoman Penyusunan Pelaporan Akuntabilias Kinerja Instansi Pemerintah,” 2003.

[2] H. Setiawan, J. E. Istiyanto, R. Wardoyo, and P. Santoso, "The use of KPI in group decision support model of ICT projects performance evaluation,” Int. Conf. Electr. Eng. Comput. Sci. Informatics, vol. 2, no. August, pp. 233-237, 2015.

[3] Urena, Raquel, et al. A review on trust propagation and opinion dynamics in social networks and group decision making frameworks. Information Sciences, 2019, 478: 461-475.

[4] Koksalmis, Emrah; KABAK, Özgür. Deriving decision makers' weights in group decision making: An overview of objective methods. Information Fusion, 2019, 49: 146-160.

[5] C. L. Hwang and M.-J. Lin, Group Decision Making under Multiple Criteria: Method and Applications, vol. 281, no. 0. Springer-Verlag, 1987.

[6] D. Turban, E; Sharda, R; Delen, Decision Support Systems, and Intelligent Systems. Boston: Prentice Hall, 2011.

[7] T. Bakshi, A. Sinharay, and B. Sarkar, "Exploratory Analysis of Project Selection through MCDM,” in ICOQM-10, 2011, pp. 128-133. 
[8] S. M. Kazemi, S. M. M. Kazemi, and M. Bahri, "Six Sigma project selections by using a Multi Criteria Decision making approach: a Case study in Poly Acryl Corp.," in Proceedings of the 41st International Conference on Computers \& Industrial Engineering, 2011, pp. 502-507.

[9] H. Ismaili, "Multi-Criteria Decision Support for Strategic Program Prioritization at Defence Research and Development Canada," University of Ottawa, 2013.

[10] E. W. N. Bernroider, N. Obwegeser, and V. Stix, "Dissemination and impact of multi-criteria decision support methods for IT project evaluation," Proc. Annu. Hawaii Int. Conf. Syst. Sci., pp. 1103-1112, 2014.

[11] J. Żak and M. Kruszyński, "Application of AHP and ELECTRE III/IV Methods to Multiple Level, Multiple Criteria Evaluation of Urban Transportation Projects," Transp. Res. Procedia, vol. 10, no. July, pp. 820-830, 2015.

[12] A. Rabbani, M. Zamani, A. Yazdani-Chamzini, and E. K. Zavadskas, "Proposing a new integrated model based on sustainability balanced scorecard (SBSC) and MCDM approaches by using linguistic variables for the performance evaluation of oil producing companies," Expert Syst. Appl., vol. 41, no. 16, pp. 7316-7327, 2014.

[13] H. S. Shih, H. J. Shyur, and E. S. Lee, "An extension of TOPSIS for group decision making," Math. Comput. Model, vol. 45, no. 7-8, pp. 801-813, 2007.

[14] R. McLeod and G. P. Schell, Management Information System, 10rd ed. New Jersey: Pearson Prentice Hall, 2007.
[15] R. Linzalone and G. Schiuma, "A review of program and project evaluation models," Meas. Bus. Excell., vol. 19, no. 3, pp. 90-99, 2015.

[16] T. Bakshi, A. Sinharay, B. Sarkar, and S. K. Sanyal, "MCDM based project selection by F-AHP \& VIKOR," Lect. Notes Comput. Sci. (including Subser. Lect. Notes Artif. Intell. Lect. Notes Bioinformatics), vol. 7076 LNCS, no. PART 1, pp. 381-388, 2011.

[17] G. Büyüközkan and A. Görener, "Evaluation of product development partners using an integrated AHP-VIKOR model," Kybernetes, vol. 44, no. 2, pp. 220-237, 2015.

[18] Project Management Institute, Project Management Institute, 2008. Guide To The Project Management Body Of Knowledge (PMBOK ${ }^{\circledR}$ GUIDE) Fourth. 1384

[19] R. E. Indrajit, "PMBOK sebagai Konsep Best Practice," vol. 37, no. C, pp. 1-37, 2013.

[20] B. Gavish and J. H. Gerdes, "Voting mechanisms and their implications in a GDSS environment," Ann. Oper. Res., vol. 71, pp. 41-74, 1997.

[21] H. Setiawan, J. Eko, R. Wardoyo, and P. Santoso, "The Group Decision Support System to Evaluate the ICT Project Performance Using the Hybrid Method of AHP, TOPSIS and Copeland Score," Int. J. Adv. Comput. Sci. Appl., vol. 7, no. 4, pp. 334-341, 2016.

[22] Azmi, Meri, et al. GDSS Prototype Model for Supplier Selection at MDM Cooperative. JOIV: International Journal on Informatics Visualization, 2021, 5.1: 16-21. 